\title{
Review
}

\section{Does the term 'trophic' actually mean anti-amyloidogenic? The case of NGF}

\author{
P Calissano ${ }^{*, 1,2,3}$, G Amadoro ${ }^{1}$, C Matrone ${ }^{1}$, S Ciafrè ${ }^{1}$, R Marolda $^{1}$, V Corsetti ${ }^{1}$, MT Ciotti ${ }^{1}$, D Mercanti ${ }^{1}$, A Di Luzio ${ }^{1}$, C Severini ${ }^{1}$, \\ C Provenzano ${ }^{1}$ and $\mathrm{N}$ Canu $^{1,3}$
}

The term trophic is widely used to indicate a general pro-survival action exerted on target cells by different classes of extracellular messengers, including neurotrophins (NTs), a family of low-molecular-weight proteins whose archetypal member is the nerve growth factor (NGF). The pro-survival action exerted by NTs results from a coordinated activation of multiple metabolic pathways, some of which have only recently come to light. NGF has been shown to exert a number of different, experimentally distinguishable effects on neurons, such as survival, differentiation of target neurons, growth of nerve fibers and their guidance (tropism) toward the source of its production. We have proposed a more complete definition of the NGF trophic action that should also include its newly discovered property of inhibiting the amyloidogenic processing of amyloid precursor protein (APP), which is among the first hypothesized primary trigger of Alzheimer's disease (AD) pathogenesis. This inhibitory action appears to be mediated by a complex series of molecular events and by interactions among NGF receptors (TrkA and p75), APP processing and tau metabolic fate and function.

Cell Death and Differentiation (2010) 17, 1126-1133; doi:10.1038/cdd.2010.38; published online 16 April 2010

\section{Trophic, Tropic and Nerve Growth-promoting Activity of NGF}

The term trophic is widely used to refer to a generalized, pro-survival action exerted on target cells by extracellular messengers of differing chemical nature such as vitamins, hormones or growth factors (GFs). Among these, neurotrophins (NTs) belong to a well-characterized family including nerve growth factor (NGF) - which was the first GF to be identified. ${ }^{1,2}$ Although the term trophic is widely used to indicate, as previously mentioned, a generalized 'nutritional' action mediated through several metabolic pathways, more detailed and in-depth experiments have indicated that this term is often too broad or ambiguous.

NGF, for instance, has been shown to exert not only its anti-apoptotic and nerve growth-promoting activity - which is the first property that led to its discovery - but it has also been subsequently identified and characterized for its more subtle, experimentally distinguishable tropic and pro-differentiative actions on its target neurons. NGF first came to light for its vigorous, extraordinary nerve growth-promoting activity on chick embryo sensory ganglia. Later, it was also reported that sympathetic ganglia degenerated and massively died when deprived of NGF with a novel and ingenious manipulation, defined as immunosympathectomy. ${ }^{3-5}$ Thus, the nerve growth-promoting action found in sensory ganglia was extended in a significantly and pronounced 'trophic' vital effect, exerted in sympathetic neurons (Figure 1). Finally, such a dual cellular effect was confirmed by the discovery that NGF was endowed with the property of directing nerve fiber growth toward the cells that produce and release it, hence the definition of tropic effect. ${ }^{6}$ Subsequent studies - performed on in vitro cultured sympathetic neurons - showed that these cells, when deprived of NGF, die due to the activation of programmed cell death. These findings provided a more specific definition of the broader term 'trophic'. ${ }^{7}$

The aim of this short review is to argue the point that an even more specific and complete definition of the antiapoptotic action exerted by NGF - and most probably by other NTs - consists in keeping under control the amyloidogenic processing of amyloid precursor protein (APP), which has been hypothesized among the primary triggers in $A D$ pathogenesis. ${ }^{8-10}$ According to this view, the pro-survival, NGF-mediated activity on its target neurons seems to consist of an inhibitory effect on amyloid- $\beta(\mathrm{A} \beta)$ peptide(s) overproduction. This appears to be sufficient in inducing several intracellular changes - involving NGF receptor itself and tau protein - that eventually lead to neuronal death.

\section{Apoptosis and Amyloidogenic APP Metabolism in AD}

$A D$ is the most common age-related neurodegenerative disorder accompanied by progressive memory and cognitive

${ }^{1}$ Institute of Neurobiology and Molecular Medicine, Via del Fosso di Fiorano 64/65, Rome 00143, Italy; ${ }^{2}$ European Brain Research Institute, Via del Fosso di Fiorano 64/65, Rome 00143 , Italy and ${ }^{3}$ Department of Neuroscience, University of Rome 'Tor Vergata', Via Montpellier 1, Rome 00133, Italy

${ }^{*}$ Corresponding author: P Calissano, European Brain Research Institute, Via del Fosso di Fiorano 64/65, Rome 00143, Italy. Tel: +390650 170 3004 ;

Fax: + 390650170 3313; E-mail: calissano@inmm.cnr.it

Keywords: NGF; $\beta$-amyloid; tau protein; apoptosis; Alzheimer's disease

Abbreviations: NTs, neurotrophins; NGF, nerve growth factor; APP, amyloid precursor protein; AD, Alzheimer's disease; SP, senile plaque; NFT, neurofibrillary tangle; $\mathrm{A} \beta$, amyloid- $\beta$

Received 27.11.09; revised 19.2.10; accepted 02.3.10; Edited by RA Knight; published online 16.4.10 

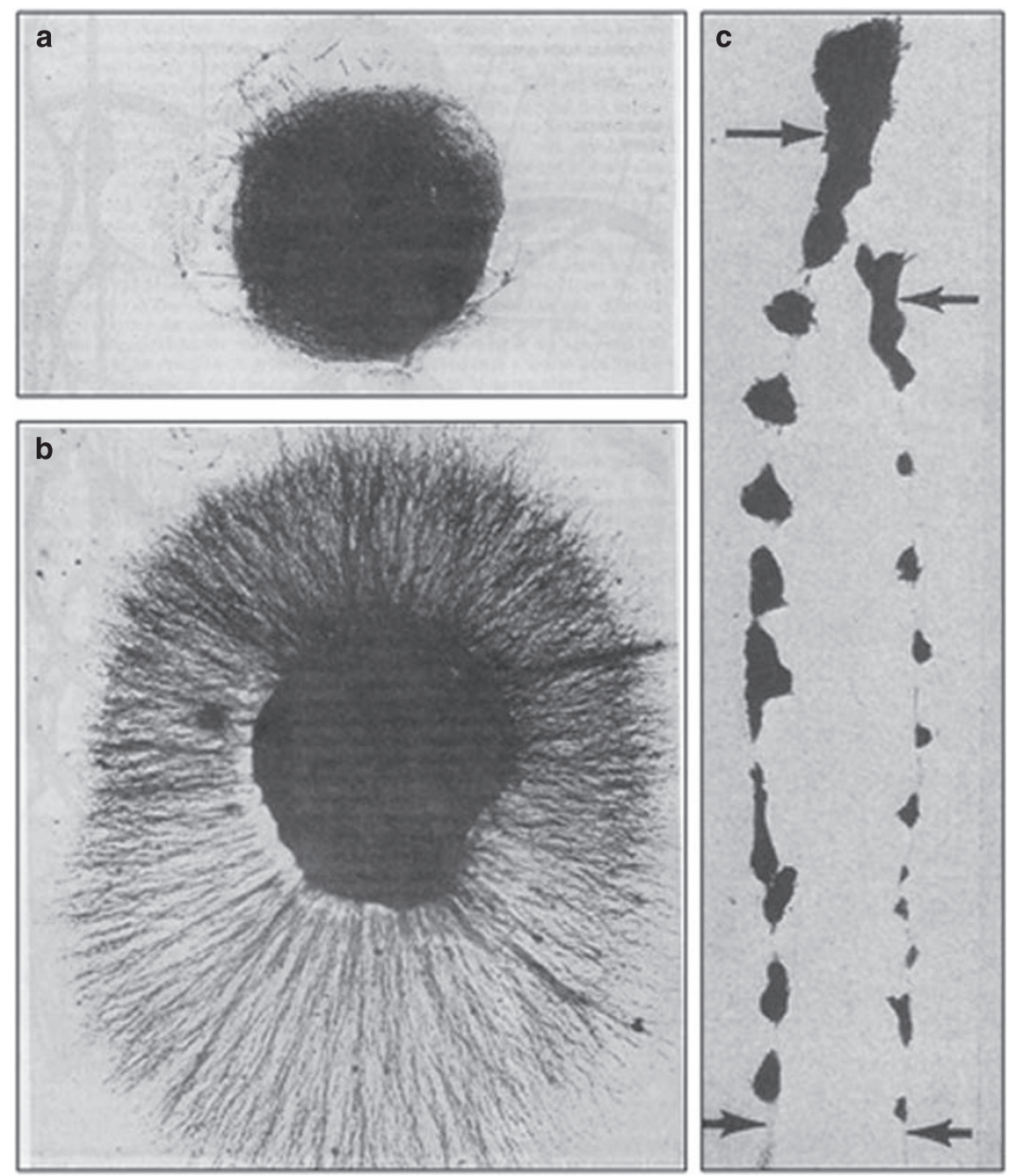

Figure 1 NGF biological assay based on its ability to induce the outgrowth of nerve fibers of isolated ganglia (from Montalcini and Calissano $0^{88}$ ). (a and $\mathbf{b}$ ) Micrographs show sensory ganglia dissected out of an 8-day-old embryo and cultured for $12 \mathrm{~h}$ either, in the absence (top) or the presence (bottom) of 10 -ng of pure NGF. After incubation the fibers were stained. (c) The two sets of ganglia shown were dissected from littermate 3-week-old mice. The control mouse (right) was injected daily with a saline solution, whereas the test mouse (left) received $10 \mu \mathrm{g} / \mathrm{g}$ of body weight of pure NGF. Chain ganglia showed a significant increase in volume

deficits. It is characterized by massive neuronal cell and synapse loss in limbic brain areas - such as hippocampus and amygdala - and also in specific cortical and subcortical regions. ${ }^{11}$ Neuropathological hallmarks are the extracellular insoluble senile plaques (SPs) - aggregated deposits of small $\mathrm{A} \beta$ peptide(s), referred to as $\mathrm{A} \beta 1-40$ or $\mathrm{A} \beta 1-42$ - and the intracellular neurofibrillary tangles (NFTs) - composed of hyperphosphorylated and truncated forms of tau protein. ${ }^{12-14}$ Extensive in vitro and in vivo genetic and biochemical studies have also unequivocally shown that $A D$ is causally linked to an altered production of $\mathrm{A} \beta$, due to a $\beta$ - and $\gamma$-secretasemediated processing of APP or to its impaired clearance. ${ }^{15}$ Furthermore, according to the 'amyloid cascade hypothesis', $\mathrm{A} \beta$ peptides have a pivotal role by promoting or exacerbating tau pathology, but their neurotoxicity is also strictly dependent on this cytoskeleton-associated protein ${ }^{16-19}$ controlling microtubule assembly and stabilization. ${ }^{20}$ A genetic component, such as mutations in several genes linked to $A D$ familial forms (APP, presenilin-1, PS1, or presenilin-2, PS2, gene) known to alter $\mathrm{A} \beta$ cellular processing or its properties, leading to an increase of the $A \beta_{42 / 40}$ ratio or its propensity to aggregate, has been shown only for a small percentage (5-8\%) of the entire population of affected patients. ${ }^{21}$

A large part of $A D$ forms are defined in being of a sporadic nature because no precise cause has been established. Moreover, the term 'sporadic' would suggest a limited incidence of $A D$ dementia whereas, on the contrary, this disease afflicts a growing number of human beings and is prospected to grow with the progressive increase of the elderly population. For instance, in the United States the number of $A D$ patients is of approximately 2.5 million and it has been anticipated that by the year 2050 it will double.

Several environmental risk factors have been hypothesized for the pathogenesis of idiopathic AD forms. Among these factors, excessive caloric intake, low scholarity, gender, apolipoprotein $E_{\varepsilon} 4$ variant, metal or pesticide exposure that could act during oxidative stress, mitochondrial damage, DNA damage/repair, altered $\mathrm{Ca}^{2+}$ homeostasis, trophic factors 
deprivation and inflammatory microglial activation. ${ }^{22}$ However, as AD is a multifactorial disorder, each of these possible age-related causes provides little possibility in developing clinical prevention and therapies. Therefore, it is likely that $A D$ will be a growing social and economic problem in the next years worldwide.

Despite the genetic evidence in favor of the amyloid hypothesis, how self-association of a misfolded protein leads to the organ dysfunction and neurodegeneration characteristic of this disorder remains to be elucidated.

\section{Alternatives to Amyloid Hypothesis}

According to the amyloid hypothesis, the accumulation and deposition of fibrillar $\mathrm{A} \beta$ is the primary trigger of neurodegeneration and cognitive decline leading to dementia. This hypothesis has been sustained by several studies, including data from genetic studies of AD. ${ }^{21}$ All four of the established $\mathrm{AD}$ genes, the $A P P$, the $P S 1, P S 2$ and $A P O E$, display mutations that increase the relative rate of production of $A \beta 42$, the longer form of the peptide that is much more prone to oligomerization and fibrillation than $A \beta 40 .{ }^{21}$ The traditional amyloid hypothesis is however debatable, mainly because spatial and temporal patterns of SP consisting of fibrillar A $\beta$ do not correlate very well with the degree of dementia in AD. In contrast, cognitive decline shows a deep relationship with loss of synaptic contacts. ${ }^{23,24}$ Recent studies highlight the 'synaptic A $\beta$ hypothesis', which underlines the pathogenic role of early assembly intermediates (non-fibrillar $\mathrm{A} \beta$ oligomers) at synapses. In this regard, reduction of synapses, due to oligomeric $\mathrm{A} \beta$, subsequent death of neurons with loss of connections and neurotransmitters cause personal devastation, memory loss and eventually dementia. ${ }^{25}$ As far as the molecular mechanisms by which oligomer $\mathrm{A} \beta$ promotes synaptotoxicity is concerned, it has been reported that $A \beta 42$ reduces, through mechanisms involving nicotine receptor and NMDA receptor, density of synapses leading to attenuated glutamatergic transmission and impaired synaptic plasticity. ${ }^{26}$ Others have suggested that $\mathrm{A} \beta$ may cause oxidative stress, which can detrimentally affect synaptic integrity. ${ }^{27}$ Therefore, in $A D$, early memory loss could be caused by early oligomeric intermediates of $\mathrm{A} \beta$-derived diffusible ligand that first disrupt synaptic plasticity and subsequently cause neuronal death by mechanisms that require specific binding and signal transduction molecules. ${ }^{28}$

\section{Amyloidogenesis and Apoptosis}

The studies linking unphysiological apoptosis and amyloidogenesis in AD initiated a decade ago, when we hypothesized that an incorrect activation of apoptosis may be the triggering cause(s) of the intracellular cascade of events leading to selective neuronal death, ${ }^{29}$ underlying such neurodegenerative disorder. To test this hypothesis, we performed preliminary experiments on primary cerebellar granule neurons (CGNs) partially deprived $(5.0 \mathrm{mM})$ of high depolarizing concentrations $(25 \mathrm{mM})$ of extracellular $\mathrm{KCl}$, a culture condition required for their in vitro survival. ${ }^{29}$ We found that apoptotic death occurred after $\mathrm{K}^{+}$starvation - possibly because it mimics the in vivo mossy fibers deafferentation induced by axotomy ${ }^{30}$ - and that this was reversible up to 4-8 $\mathrm{h}$ after treatment with high concentration of $\mathrm{KCl}$, forskolin and IGF-1. ${ }^{29}$ Neuronal loss was characterized by de novo RNA/protein synthesis and coordinated gene expression, ${ }^{31}$ nuclear condensation and fragmentation, decrease of intracellular free calcium levels ${ }^{32}$ and by an imbalance of the physiological APP metabolism toward the amyloidogenic noxious counterpart. The amount of $\alpha$ APPs (the 'good' form of APP generated by $\alpha$-secretase-mediated pathway) released in conditioned apoptotic medium was significantly decreased, whereas $\beta$ APPs (the 'bad' form of APP produced by $\beta$ - $\gamma$-secretase-mediated cleavage) inversely increased, in the absence of any significant change of intracellular level of full-length APP. ${ }^{33}$ The overproduced extracellular $4 \mathrm{kDa}$ $\mathrm{A} \beta$ peptides (A $\beta 1-40 ; \mathrm{A} \beta 1-42)$ aggregated into oligomeric and high-molecular-weight species of different size and morphology.

Contextually, tau protein post-translational modifications such as site-specific change of its phosphorylation state and caspase(s) and calpain-I-mediated cleavage - occurred with a consequent microtubule disassembly in dying neurons. ${ }^{34}$ Furthermore, if one of such truncated tau forms was introduced into the same healthy neurons by adenovirusmediated transduction, it evoked a massive and rapid cell death $^{35}$ involving extrasynaptic NR2B-subunit-containing NMDARs, dephosphorylation of cAMP-response-elementbinding protein, sustained and delayed activation of extracellular-regulated kinases $1 / 2$ and calpain-I. ${ }^{36}$

In addition, the pro-apoptotic shifting to a low potassium medium induced a marked failure of mitochondrial oxidative phosphorylation, accompanied by a dramatic intracellular ATP drop and by an increased production of reactive oxidative species. ${ }^{37-39}$ A functional impairment of proteasomes, causing a progressive accumulation of ubiquitinated-unfolded proteins in the cytoplasm, ${ }^{40}$ and an early perturbation of autophagiclysosomal structures were also revealed in apoptotic neurons. ${ }^{41}$ Interestingly, co-culture experiments showed that an $\mathrm{A} \beta$ antibody partially inhibited the 'transfer' of apoptotic process to healthy, but separated neighboring neurons. This finding suggested that the $\mathrm{A} \beta$ pool released by apoptotic neurons diffused to the healthy cells, creating an autocrine toxic loop (Figure 2). ${ }^{42}$

\section{NGF as an Anti-amyloidogenic factor: the NGF-PC12 system}

NGF-differentiated rat PC12 cells represent an excellent experimental cellular model to investigate the NGF biological properties and its mechanism of action. ${ }^{43}$ This clonal cell line undergoes a progressive mitotic arrest and neuronal differentiation when incubated with NGF and dies when this NT is withdrawn from the culture medium. ${ }^{43}$

As it was interesting to assess whether such apoptotic events would be followed by, or be due to, excessive $\mathrm{A} \beta$ production, as previously reported in CGNs, we carried out similar set of experiments in this in vitro apoptotic paradigm. We found that a parallel release and accumulation of secreted $\mathrm{A} \beta$ peptide(s) - with prevalence of $\mathrm{A} \beta 1-42$ over $\mathrm{A} \beta 1-40$ peptides - occurred during the progressive death of NGF-deprived differentiated PC12 cells. The released pool 
a

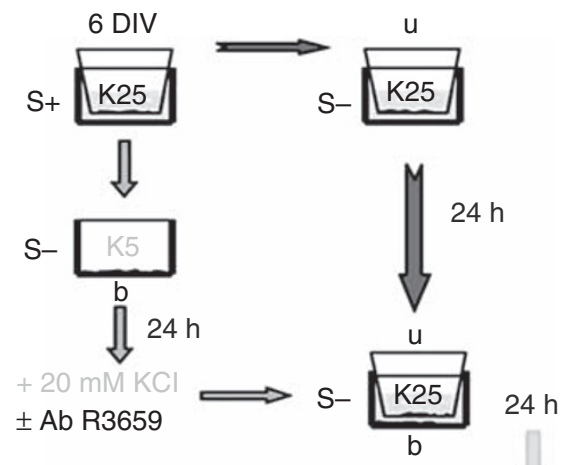

Viable cells count

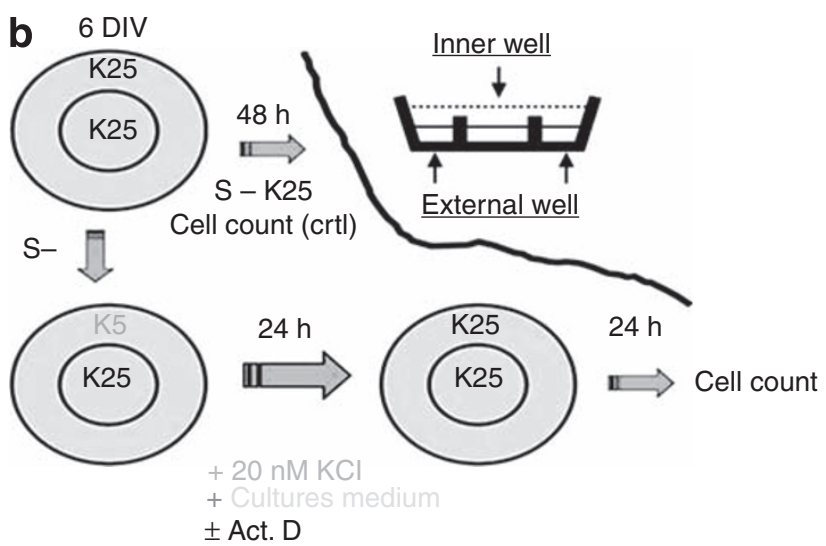

Figure 2 Transwell (a) and two-well dish (b) are the sister cultures in vitro model for apoptotic cerebellar granule neurons (CGNs) (from De Berardinis et al. ${ }^{42}$ ). (a) CGNs at 6 DIV (upper wells) were transferred in sister cultures kept in S-K25 whereas the correspondent co-cultured neurons (bottom wells) were switched to apoptotic S-K5 medium. After $24 \mathrm{~h}$ incubation, conditioned medium of bottom wells was supplemented with $\mathrm{KCl}$ to a final concentration of $25 \mathrm{mM}$ in the presence or absence of specific $\mathrm{A} \beta$ polyclonal antibody or pre-immune rabbit antiserum, respectively, and the upper sister compartments were then transferred back and co-incubated for a further $24 \mathrm{~h}$. Neuronal viability was measured by MTT assay and intact count nuclei. (b) CGNs at 6 DIV were shifted either to S-K25 (control cultures), or to S-K5 (apoptotic cultures) for $24 \mathrm{~h}$. External compartment conditioned medium was reported to S-K25 and the volume was increased until the two chambers were in communication with each other. After $24 \mathrm{~h}$, neuronal viability was assayed as described previously

of $A \beta$, isolated on ultracentrifugation, was also found to form aggregates of different molecular size that were partially SDSresistant and moderately soluble in formic acid $(70 \%)$, a condition generally used to dissolve $A \beta$-positive aggregates extracted in vivo from human SP of AD subjects. ${ }^{44}$ The secreted $\mathrm{A} \beta$ seemed also to affect healthy neurons, in a similar manner to that previously found in CGC, prompting the setup of experimental conditions to answer the following question: if $A \beta$ is the upstream trigger - a molecular 'killer' of healthy neurons - could its inhibition reduce or block the timing/extent of cell death occurring after NGF deprivation? We found that the downregulation of amyloidogenic APP processing with selective $\beta$ - and $\gamma$-secretase(s) inhibitors or $4 G 8$ antibody (A $\beta$ residues $17-24)$ significantly reduced the apoptotic death of NGF-deprived PC12 neurons. ${ }^{45}$ In our opinion, these results not only provide the first clear evidence linking apoptosis and amyloidogenic APP metabolism, but also gives new insights into the causal and temporal sequence of events occurring during neuronal death induced by the lack of trophic supply.

Having established the 'active' role of $\mathrm{A} \beta$ peptide in neuronal death, a still unresolved problem was: do caspase(s) work upstream, the amyloidogenic APP derouting evoked by NGF deprivation or do they become part of the scenario only at a later stage, when $\mathrm{A} \beta$ has already - so to speak - prepared the action field for their subsequent effects? Previous studies have shown that caspase 3-mediated APP cleavage at APP $720^{46}$ directly elevated $A \beta$ production in serum-deprived human neuronal NT2 cells. Intracellular post-translational depletion of GGA3 - an adaptor protein that is required for BACE (namely $\beta$-secretase) lysosomal degradation - after caspase 3-dependent truncation, prolonged the half-life of such enzyme and indirectly enhanced $A \beta$ generation in staurosporine-treated H4-APP751 cell line. ${ }^{47}$ Conversely, among all cell-permeable and selective caspase(s) inhibitors tested in NGF-deprived PC12, only blockage of executor caspases 2, 12, 6 and 8 partially reduced death and $A \beta$ production, whereas pharmacological inhibition of effector caspase 3 did not exert a similar action. ${ }^{45}$ Apoptosis induced by serum deprivation or by oxygen peroxide treatment under mild exposure conditions, at variance with NGF, evoked an apoptotic neuronal death that was not inhibited by $\beta$ - and $\gamma$-secretase inhibitors or by $4 \mathrm{G} 8$ antibody. Finally, the finding that the general caspase(s) inhibitor z-VAD did not significantly affect the production of $A \beta$ structure and cell death in NGF-deprived PC12, whereas it partially blocked caspase(s)-mediated tau truncation ${ }^{48}$ and rescued neurons from apoptotic death ${ }^{45}$ suggests a complex causal and temporal relationship between caspase(s), APP amyloidogenic processing and tau metabolism in NGF-deprived cell death. Therefore, whether caspase(s) activation is a terminal process associated with neuronal death, or a more proximal event that promotes the AD-like pathology in these cells, remains to be still proven.

\section{NGF-deprived Hippocampal Neurons: the Amyloid Cascade and tau Involvement}

The actual link between apoptosis and amyloidogenesis is further corroborated in NGF-deprived primary hippocampal cultures, a neuronal population directly affected in human AD patients, which underlies the anatomopathological and clinical signs of such neurodegenerative dementia. ${ }^{49-52}$

In a preliminary set of in vitro experiments, we attempted to confirm data previously obtained in NGF-differentiated PC12 cells. Thus, even in NGF-deprived hippocampal neurons, we observed that (1) the released $\mathrm{A} \beta$ extracellular peptides created a neurotoxic loop, because the extent of ensuing cell death was much greater than that expected on the potential number of NGF-responsive target neurons previously found; (2) $\beta$ - or $\gamma$-secretase inhibitors - or mixture of both - and $A \beta$ antibody, 4G8, largely prevented not only the $A \beta$ intra- and extra-production but also neuronal death. ${ }^{53}$ The temporal interplay between $A \beta$ overproduction and tau protein post-translational modifications was also established from the observation that two specific amino-acidic sites 
(Ser 262 and Thr 231) - pathognomonic of abnormal AD-like tau protein detected in aggregated insoluble intracellular NFTs - were rapidly (3-6h) and transiently $(<12 \mathrm{~h})$ hyperphosphorylated in hippocampal neurons on NGF withdrawal. The early, specific and temporally restricted phosphorylation state changes of tau were (1) temporally related to a decrease of the ratio of secreted $\alpha$ APPs/ $\beta$ APPs; (2) caused by a deregulation of Akt-GSK3 $\beta$ signaling, known to be in vivo correlated with the onset of $A D$ pathology; (3) mimicked by externally added synthetic $A \beta 1-42$ peptide, but not by reversesequence peptide $\mathrm{A} \beta$ 42-1; (4) sensitive to $\mathrm{LiCl}$ treatment and, more importantly, (5) significantly reduced on treatment with $\mathrm{A} \beta$ antibodies or with $\beta$ - and $\gamma$-secretase(s) inhibitors. ${ }^{54}$ The increased pool of hyperphosphorylated tau, which is unable to bind microtubules, subsequently detached from them, as shown by the reduction in the intracellular level of acetyl (stable)-tubulin and by a concomitant increase of its $\alpha$-tyrosinylated (instable) form. Contextually, a progressive disassembly of the cytoskeleton network occurred and the microtubule tracks-based axonal transport was acutely impaired, as shown from observing that mitochondria accumulated in the perykaryon and were no longer transported along axonal processes. ${ }^{54}$

The tau-dependent loss of microtubule integrity and axonal neuritic beading associated with jamming of mitochondria were also partially rescued by the treatment with $A \beta$-antibody and GSK3 $\beta$ inhibitors. In addition, calpain-I and caspase 3 protease(s) were only late upregulated and pharmacological inhibition of such apoptotic proteases not only partially protected hippocampal neurons from death after the NGF removal, but also did not significantly interfere with GSK3 $\beta$-mediated site-specific tau hyperphosphorylation. This suggests that the delayed caspase 3/calpain-I pathway does not regulate GSK3 $\beta$-dependent changes of tau phosphorylation state, ${ }^{54}$ in agreement with previous studies reporting that, in differentiated PC12 induced to cell death by NGF deprivation, the GSK3 $\beta$ kinase inhibition only exerted a small effect on the caspase(s) pathway. ${ }^{55}$

An early tau hyperphosphorylation, with a reduction of its microtubule binding affinity has been found in NGF-deprived differentiated $\mathrm{PC} 12$ cells. ${ }^{56}$ In addition, although other research groups have reported that $A \beta$ antibodies can reduce tau hyperphosphorylation in vitro and in vivo, ${ }^{57,58}$ the functional relationship between endogenous overproduced $\mathrm{A} \beta$, tau hyperphosphorylation/cleavage and apoptotic signaling in the same neuronal model has not been investigated before. Similar NGF-dependent modifications of site-specific tau phosphorylation have been found in the AD11 animal model, ${ }^{54}$ in correlation with the temporal appearance of $A \beta$ peptide species. ${ }^{59}$ Interestingly, these anti-NGF transgenic AD11 mice, in which the in vivo phenotypic knockout of mature NGF is achieved by the expression of recombinant neutralizing antibodies, resemble an AD-like neurodegeneration. ${ }^{60,61}$ Furthermore, a caspase(s)-mediated truncation of N-terminal tau domain, which possibly interacts with dynactin/dynein motor complex, ${ }^{62}$ also occurs in vitro and in vivo on NGF signaling interruption. ${ }^{48}$ GSK3 $\beta$-mediated tau phosphorylation is associated with a proper anterograde organelle transport ${ }^{63}$ in NGF-dependent differentiated PC12, and synthetic $\mathrm{A} \beta$ peptides cause a GSK3 $\beta$-mediated impairment of mitochondrial transport in hippocampal cultured neurons. ${ }^{64}$ Finally, a mislocalization of pThr 231-tau protein and GSK3 $\beta$ in basal forebrain cholinergic neurons of aged rats is causally linked to an in vivo defective retrograde axonal transport. ${ }^{64,65}$

\section{Paradoxical, unexpected Functional Switch of the TrkA Receptor}

TrkA belongs to the large family of tyrosine kinases transmembrane receptors sharing, as a common denominator, the property of trans-autophosphorylating on binding to their cognate ligand. Receptor engagement with its specific NT changes the inactive conformation into an active state, which triggers and activates the appropriate signal transduction pathway(s) by recruiting intracellular adaptor proteins, effectors or both. The active conformation regains its inactive, dephosphorylated state within minutes after the extracellular concentration of ligand decreases to a value favoring the free unbound state. ${ }^{66,67}$ It was therefore an unexpected finding that, $24 \mathrm{~h}$ after NGF withdrawal, TrkA regained its phosphorylated state (pY490) in the apoptotic hippocampal primary neurons contextually to (1) an Akt dephosphorylation, (2) an upregulation of phospholipase- $\mathrm{C} \gamma(\mathrm{PLC} \gamma)$ pathway and (3) the progression of neuronal death. ${ }^{68}$ This paradoxical, NGF-independent delayed TrkA phosphorylation could be assumed either as a side effect of death-inducing changes evoked by NGF withdrawal, or as an intracellular signaling linked to $\mathrm{A} \beta$ increase. In subsequent experiments we confirmed this latter hypothesis. Incubation of NGF-deprived neurons with two different TrkA antagonists, namely K252 and CEP-2563, generally used to inhibit TrkA autophosphorylation, largely protected hippocampal cultures from apoptotic death. Furthermore, an identical anomalous TrkA posttranslational modification was evoked in neurons by exogenously added synthetic $\mathrm{A} \beta$ peptide, suggesting a causal relationship between NGF withdrawal, amyloidogenic APP metabolism and NGF-independent TrkA phosphorylation. Similarly, partial TrkA mRNA silencing paradoxically favored neuronal survival, suggesting that the NGF receptor may switch from pro-survival to pro-apoptotic action in the absence of its specific ligand. In addition, pharmacological inhibition of Cdk and Src kinases, known to trigger amyloidogenesis by affecting APP phosphorylation and processing, ${ }^{69-72}$ reduced the TrkA and PLC $\gamma$ phosphorylation levels and rescued neuronal cultures from death. Relevantly, in p75-silenced neurons, TrkA did not appear phosphorylated after NGF removal and the interruption of the amyloidogenic pathway was prevented. ${ }^{68}$ Furthermore, in early periods after NGF removal, p75 and particularly CTF - its C-terminal fragment produced by $\alpha$-secretase cleavage ${ }^{73}$ - bound $A \beta$ peptides and $28 \mathrm{kDa}$ PS1 fragment (one of the components of $\gamma$-secretase complex ${ }^{74}$ ) and led to apoptotic death. ${ }^{68}$ These findings further support data previously reported about a p75 role as an early mediator of the toxic $A \beta^{75}$ effect and support the working hypothesis of a possible imbalance in secretase(s) activity as a possible cause triggering the amyloidogenic pathway activation. $^{76}$

Together, these results also seem to open a new paradigm in the field of NGF intracellular signal transduction, because the same TrkA transmembrane receptor may switch from 


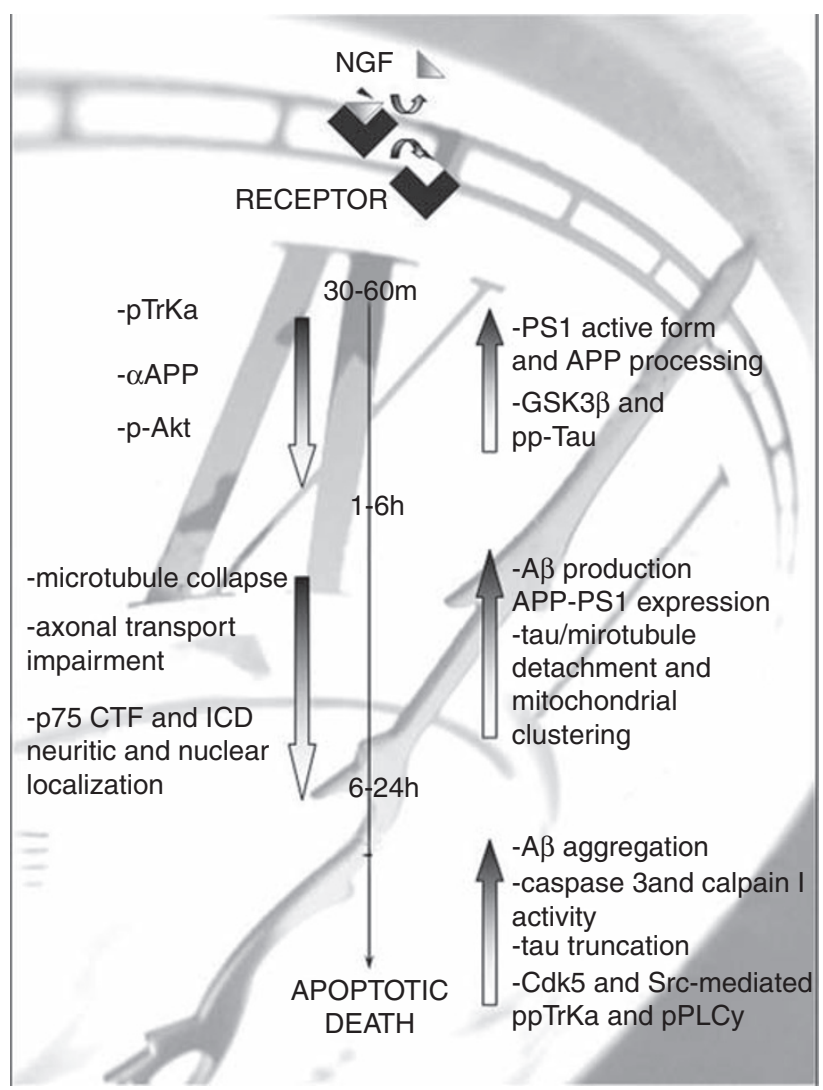

Figure 3 Schematic drawing of a hypothesized temporal cascade of molecular and biochemical events occurring in NGF-deprived hippocampal neurons. After NGF withdrawal, amyloidogenic APP processing with $A \beta$ production early occurred in cultured hippocampal neurons. An intracellular p75 processing, that leads to C-terminal (CTF) and intracellular domain (ICD) fragments, also was detected. CTF p75 fragment bounded with the $A \beta$ peptides, whereas ICD p75 fragment co-localized with PSEN1 active forms into the nucleus. An NGF-independent/A $\beta$ mediated TrkA receptor hyperphosphorylation correlated with Cdk and Src activation, concomitantly with AKT dephosphorylation and related PLC phosphorylation. Neurotrophin removal also induced AKT-mediated GSK3 $\beta$ activation, which - in turn - caused the site-specific tau protein phosphorylation at Ser 262 and Thr 231 epitopes. The reduced microtubule-binding affinity of hyperphosphorylated tau evoked the cytoskeleton collapse and the axonal transport impairment. Morphological and biochemical signs of classical apoptotic - namely caspase(s)-calpain I protease(s) activation and nuclear condensation - were only later detectable

pro-survival to pro-apoptotic action, in the presence or absence of its physiological cognate ligand. In addition, the evidence that NGF receptors, directly or indirectly, interact with $A \beta$ peptide(s) and PS1 in apoptotic neurons and that analogous effects are induced by synthetic $\mathrm{A} \beta$ exogenously added peptide ${ }^{53,68}$ corroborates the ongoing hypothesis of a cellular interplay between the NGF receptors (TrkA and p75) and the amyloidogenic APP processing machinery (Figure 3). ${ }^{77}$

\section{NGF as a Potential Therapeutic Agent for AD: in vivo Validation}

A deficit in NT is largely related to AD. ${ }^{22}$ NTs, such as NGF and BDNF, are acquiring a strong relevance due their crucial role in cortical and hippocampal plasticity and, ultimately, on behavior. Indeed, it has been reported that they exert neurotrophic actions on the cholinergic neurons of the basal forebrain, protecting them also against axotomy-induced neurodegeneration and age-related atrophy. ${ }^{78,79}$ Moreover, NGF as well as BDNF has been reported to increase hippocampal neurogenesis, in adult and aged male rat. ${ }^{52,80}$ Altogether, these findings are recently prospecting a new approach to prevent neuroplasticty impairment and cell death in $A D{ }^{22}$

In vivo studies indicate NGF as therapeutic tool for targeting AD pathology. The intranasal administration of NGF and oral administration of two AchE inhibitors - ganstigmine and donepezil - improve the performance of two tests related to hippocampal function (for place and context for object recognition and memory) in AD11 mouse. ${ }^{81}$ Relevantly, the drug is in phase Ila studies in the United States for senile dementia associated with Alzheimer's disease (AD). ${ }^{82}$ One of the main problem related to NGF administration in vivo is the large dimension of this molecule that does not easily cross the blood-brain barrier, and on the short half-life. Therefore, delivery of neurotrophic factors to the brain remains a major challenge. For this reason, to facilitate the supply of NGF to the brain, many new protein delivery technologies have been developed. Among them, encouraging prospective derives from implantation, into the forebrain of patients with mild $A D$, of autologous fibroblasts genetically modified to express human NGF. ${ }^{83}$ Indeed, treated $\mathrm{AD}$ cases manifested an improvement of cognitive deficit, in absence of any long-term adverse effects. Moreover, new small molecules have been recently identified to modulate NGF receptor signaling in AD. ${ }^{84}$ Particularly, a non-peptidyl mimetic of the NT loop 1 domain (LM11A-24) promotes p75 ${ }^{\mathrm{NTR}}$-mediated survival in hippocampal neuron and interferes with $\mathrm{p} 75^{\mathrm{NTR}}$-mediated apoptosis induced by proNGF in oligodendrocytes. ${ }^{85}$ In addition, neurotrophic factor-loaded microspheres have been used for the experimental treatment of some neurological disorders. ${ }^{86}$ Recombinant human NGF-loaded microspheres, implanted into the basal forebrain of the rats with fimbria-fornix lesion, induced a significant increase on the survival of axotomized cholinergic neurons in the medial septum and vertical diagonal branch. ${ }^{87} \mathrm{All}$ together, these in vivo data strongly support and encourage the therapeutic use of NGF for the AD prevention and cure.

\section{Conflict of interest}

The authors declare no conflict of interest.

Acknowledgements. This research was supported by grants from Ceinge and PRIN to PC and by grant ex. Art. 56522F/B/1 to NC

1. Cohen $S$, Levi-Montalcini $R$, Hamburger $V$. A nerve growth-stimulating factor isolated from sarcoma AS 37 and 180. Proc Natl Acad Sci USA 1954; 40: 1014-1018.

2. Levi-Montalcini R. Nerve growth factor. Science 1975; 187: 113.

3. Cohen S, Levi-Montalcini R. A nerve growth-stimulating factor isolated from snake venom. Proc Natl Acad Sci USA 1956; 42: 571-574.

4. Levi-Montalcini R, Booker B. Destruction of the sympathetic ganglia in mammals by antiserum to a nerve growth protein. Proc Natl Acad Sci USA 1960; 46: 384-391.

5. Levi-Montalcini $R$, Calissano $P$. The nerve growth factor as a paradigm of polypeptide growth factors. Trends Neurosci 1986; 8: 473-477. 
6. Claude $P$, Hawrot E, Dunis DA, Campenot RB. Binding, internalization, and retrograde transport of 125I-nerve growth factor in cultured rat sympathetic neurons. J Neurosci 1982; 2: $431-442$.

7. Yip HK, Rich KM, Lampe PA, Johnson Jr EM. The effects of nerve growth factor and its antiserum on the postnatal development and survival after injury of sensory neurons in rat dorsal root ganglia. J Neurosci 1984; 4: 2986-2992.

8. Walsh DM, Selkoe DJ. A $\beta$ oligomers - a decade of discovery. J Neurochem 2007; 101: 1172-1184. Review.

9. Eckman CB, Eckman EA. An update on the amyloid hypothesis. Neurol Clin 2007; 25: 669-682. Review.

10. Hardy J, Selkoe DJ. The amyloid hypothesis of Alzheimer's disease: progress and problems on the road to therapeutics. Science 2002; 297: 353-356

11. Selkoe DJ. Alzheimer's disease: genes, proteins, and therapy. Physiol Rev 2001; 81: 741-766. Review.

12. Walsh DM, Selkoe DJ. Deciphering the molecular basis of memory failure in Alzheimer's disease. Neuron 2004; 44: 181-193. Review.

13. Thinakaran G, Koo EH. Amyloid precursor protein trafficking, processing, and function. J Biol Chem 2008; 283: 29615-29619.

14. Iqbal K, Grundke-lqbal I. Alzheimer neurofibrillary degeneration: significance, etiopathogenesis, therapeutics and prevention. J Cell Mol Med 2008; 12: 38-55. Review.

15. Haass C, Selkoe DJ. Soluble protein oligomers in neurodegeneration: lessons from the Alzheimer's amyloid beta-peptide. Nat Rev Mol Cell Biol 2007; 8: 101-112. Review.

16. Götz J, Ittner LM, Schonrock N, Cappai R. An update on the toxicity of A $\beta$ in Alzheimer's disease. Neuropsychiatr Dis Treat 2008; 4: 1033-1042.

17. Rapoport M, Dawson HN, Binder LI, Vitek MP, Ferreira A. Tau is essential to beta-amyloid-induced neurotoxicity. Proc Natl Acad Sci USA 2002; 99: 6364-6369.

18. Roberson ED, Scearce-Levie K, Palop JJ, Yan F, Cheng IH, Wu T et al. Reducing endogenous tau ameliorates amyloid beta-induced deficits in an Alzheimer's disease mouse model. Science 2007; 316: 750-754.

19. King ME, Kan HM, Baas PW, Erisir A, Glabe C, Bloom G. Tau-dependent microtubule disassembly initiated by prefibrillar beta-amyloid. J Cell Biol 2006; 20: 541-546.

20. Stoothoff WH, Johnson GV. Tau phosphorylation: physiological and pathological consequences. Biochim Biophys Acta 2005; 1739: 280-297.

21. Bertram L, Tanzi RE. Thirty years of Alzheimer's disease genetics: the implications of systematic meta-analyses. Nat Rev Neurosci 2008; 9: 768-778. Review.

22. Calissano $P$, Matrone $C$, Amadoro G. Apoptosis and in vitro Alzheimer disease neuronal models. Comm Integr Biol 2009; 2: 163-169.

23. Shankar GM, Walsh DM. Alzheimer's disease: synaptic dysfunction and Abeta. Mol Neurodegener 2009; 4: 48.

24. Hu NW, Smith IM, Walsh DM, Rowan MJ. Soluble amyloid-beta peptides potently disrupt hippocampal synaptic plasticity in the absence of cerebrovascular dysfunction in vivo. Brain 2008; 131 (Part 9): 2414-2424.

25. Querfurth HW, LaFerla FM. Alzheimer's disease. N Engl J Med 2010; 362: 329-344. Review.

26. Snyder EM, Nong Y, Almeida CG, Paul S, Moran T, Choi EY et al. Regulation of NMDA receptor trafficking by amyloid-beta. Nat Neurosci 2005; 8: 1051-1058.

27. Lee HG, Moreira PI, Zhu X, Smith MA, Perry G. Staying connected: synapses in Alzheimer disease. Am J Pathol 2004; 165: 1461-1464. Review.

28. Walsh DM, Klyubin I, Fadeeva JV, Cullen WK, Anwyl R, Wolfe MS et al. Naturally secreted oligomers of amyloid beta protein potently inhibit hippocampal long-term potentiation in vivo. Nature 2002; 416: 535-539.

29. D'Mello S, Galli C, Ciotti MT, Calissano P. Induction of apoptosis in cerebellar granule neurons by low potassium: inhibition of death by insulin-like growth factor I and cAMP. Proc Natl Acad Sci USA 1993; 90: 10989-10993.

30. Borsello T, Di Luzio A, Ciotti MT, Calissano P, Galli C. Granule neuron DNA damage following deafferentation in adult rats cerebellar cortex: a lesion model. Neuroscience 2000; 95: 163-171.

31. Cavallaro S, Calissano P. A genomic approach to investigate neuronal apoptosis. Curr Alzheimer Res 2006; 3: 4-23.

32. Galli C, Meucci O, Scorziello A, Werge TM, Calissano P, Schettini G. Apoptosis in cerebellar granule cells is blocked by high $\mathrm{KCl}$, Forskolin, and IGF-1 through distinct mechanisms of action: the involvement of intracellular calcium and RNA synthesis. J Neurosci 1995; 15: 1172-1179.

33. Galli C, Piccini A, Ciotti MT, Castellani L, Calissano P, Zaccheo D et al. Increased amyloidogenic secretion in cerebellar granule cells undergoing apoptosis. Proc Natl Acad Sci USA 1998; 95: 1247-1252.

34. Canu N, Dus L, Barbato C, Ciotti MT, Brancolini C, Rinaldi AM et al. Tau cleavage and dephosphorylation in cerebellar granule neurons undergoing apoptosis. J Neurosci 1998; 18: 7061-7074.

35. Amadoro G, Serafino AL, Barbato C, Ciotti MT, Sacco A, Calissano P et al. Role of $\mathrm{N}$-terminal tau domain integrity on the survival of cerebellar granule neurons. Cell Death Differ 2004; 11: 217-230.

36. Amadoro G, Ciotti MT, Costanzi M, Cestari V, Calissano P, Canu N. NMDA receptor mediates tau-induced neurotoxicity by calpain and ERK/MAPK activation. Proc Natl Acad Sci USA 2006; 103: 2892-2897.
37. Atlante A, Gagliardi S, Marra E, Calissano P. Neuronal apoptosis in rats is accompanied by rapid impairment of cellular respiration and is prevented by scavengers of reactive oxygen species. Neurosci Lett 1998; 245: 127-130.

38. Bobba A, Atlante A, Giannattasio S, Sgaramella G, Calissano P, Marra E. Early release and subsequent caspase-mediated degradation of cytochrome $c$ in apoptotic cerebellar granule cells. FEBS Lett 1999; 457: 126-130.

39. Atlante A, De Bari L, Bobba A, Marra E, Calissano P, Passarella S. Cytochrome c, released from cerebellar granule cells undergoing apoptosis or excytotoxic death, can generate protonmotive force and drive ATP synthesis in isolated mitochondria. J Neurochem 2003; 86: $591-604$

40. Canu N, Barbato C, Ciotti MT, Serafino A, Dus L, Calissano P. Proteasome involvement and accumulation of ubiquitinated proteins in cerebellar granule neurons undergoing apoptosis. J Neurosci 2000; 20: 589-599.

41. Canu N, Tufi R, Serafino AL, Amadoro G, Ciotti MT, Calissano P. Role of the autophagiclysosomal system on low potassium-induced apoptosis in cultured cerebellar granule cells. J Neurochem 2005; 92: 1228-1242.

42. De Berardinis MA, Ciotti MT, Amadoro G, Galli C, Calissano P. Transfer of the apoptotic message in sister cultures of cerebellar neurons. Neuroreport 2001; 12 : 2137-2140.

43. Greene LA, Tischler AS. Establishment of a noradrenergic clonal line of rat adrenal pheochromocytoma cells which respond to nerve growth factor. Proc Natl Acad Sci USA 1976; 73: 2424-2428.

44. Kuo M, Emmerling MR, Vigo-Pelfrey C, Kasunic TC, Kirkpatrick JB, Murdoch GH et al. Water-soluble Abeta (N-40, N-42) oligomers in normal and Alzheimer disease brains. J Biol Chem 1996; 271: 4077-4081.

45. Matrone C, Di Luzio A, Meli G, D'Aguanno S, Severini C, Ciotti MT et al. Activation of the amyloidogenic route by NGF deprivation induces apoptotic death in PC12 cells. $J$ Alzheimers Dis 2008; 13: 81-96.

46. Gervais FG, Xu D, Robertson GS, Vaillancourt JP, Zhu Y, Huang J et al. Involvement of caspases in proteolytic cleavage of Alzheimer's amyloid-beta precursor protein and amyloidogenic A beta peptide formation. Cell 1999; 97: 395-406.

47. Tesco G, Koh YH, Kang EL, Cameron AN, Das S, Sena-Esteves M et al. Depletion of GGA3 stabilizes BACE and enhances beta-secretase activity. Neuron 2007; 54: 721-737.

48. Corsetti V, Amadoro G, Gentile A, Capsoni S, Ciotti MT, Cencioni MT et al. Identification of a caspase-derived $\mathrm{N}$-terminal tau fragment in cellular and animal Alzheimer's disease models. Mol Cell Neurosci 2008; 38: 381-392.

49. Morrison JH, Hof PR. Selective vulnerability of corticocortical and hippocampal circuits in aging and Alzheimer's disease. Prog Brain Res 2002; 136: 467-486.

50. Scheff SW, Price DA. Alzheimer's disease-related alterations in synaptic density: neocortex and hippocampus. J Alzheimers Dis 2006; 9 (3 Suppl): 101-115.

51. Scheff SW, Price DA, Schmitt FA, Mufson EJ. Hippocampal synaptic loss in early Alzheimer's disease and mild cognitive impairment. Neurobiol Aging 2006; 27: 1372-1384.

52. Frielingsdorf $\mathrm{H}$, Simpson DR, Thal LJ, Pizzo DP. Nerve growth factor promotes survival of new neurons in the adult hippocampus. Neurobiol Dis 2007; 26: 47-55.

53. Matrone C, Ciotti MT, Mercanti D, Marolda R, Calissano P. NGF and BDNF signaling control amyloidogenic route and Abeta production in hippocampal neurons. Proc Natl Acad Sci USA 2008; 105: 13139-13144.

54. Amadoro G, Corsetti V, Ciotti MT, Florenzano F, Capsoni S, Amato G et al. Endogenous Abeta causes cell death via early tau hyperphosphorylation. Neurobiol Aging 2009. (doi:10.1016/j.neurobiolaging.2009.06.005).

55. Bhat RV, Leonov S, Luthman J, Scott CW, Lee CM. Interactions between GSK3beta and caspase signaling pathways during NGF deprivation induced cell death. J Alzheimers Dis 2002; 4: 291-301.

56. Shelton SB, Johnson GV. Tau and HMW tau phosphorylation and compartmentalization in apoptotic neuronal PC12 cells. J Neurosci Res 2001; 66: 203-213.

57. Ma QL, Lim GP, Harris-White ME, Yang F, Ambegaokar SS, Ubeda OJ et al. Antibodies against beta-amyloid reduce Abeta oligomers, glycogen synthase kinase-3beta activation and tau phosphorylation in vivo and in vitro. J Neurosci Res 2006; 83: 374-384.

58. Oddo S, Billings L, Kesslak JP, Cribbs DH, LaFerla FM. Abeta immunotherapy leads to clearance of early, but not late, hyperphosphorylated tau aggregates via the proteasome. Neuron 2004; 43: 321-332.

59. Capsoni S, Giannotta S, Cattaneo A. Beta-amyloid plaques in a model for sporadic Alzheimer's disease based on transgenic anti-nerve growth factor antibodies. Mol Cell Neurosci 2002; 21: 15-28.

60. Capsoni S, Giannotta S, Cattaneo A. Early events of Alzheimer-like neurodegeneration in anti-nerve growth factor transgenic mice. Brain Aging 2002; 2: 24-43.

61. Ruberti F, Capsoni S, Comparini A, Di Daniel E, Franzot J, Gonfloni S et al. Phenotypic knockout of nerve growth factor in adult transgenic mice reveals severe deficits in basal forebrain cholinergic neurons, cell death in the spleen, and skeletal muscle dystrophy. J Neurosci 2000; 20: 2589-2601.

62. Magnani E, Fan J, Gasparini L, Golding M, Williams M, Schiavo G et al. Interaction of tau protein with the dynactin complex. EMBO J 2007; 26: 4546-4554.

63. Tatebayashi Y, Haque N, Tung YC, Iqbal K, Grundke-Iqbal I. Role of tau phosphorylation by glycogen synthase kinase-3beta in the regulation of organelle transport. J Cell Sci 2004; 117: $1653-1663$. 
64. Niewiadomska G, Baksalerska-Pazera M, Riedel G. Cytoskeletal transport in the aging brain: focus on the cholinergic system. Rev Neurosci 2006; 17: 581-618.

65. Niewiadomska G, Baksalerska-Pazera M, Riedel G. Altered cellular distribution of phospho-tau proteins coincides with impaired retrograde axonal transport in neurons of aged rats. Ann N Y Acad Sci 2005; 1048: 287-295.

66. Chao MV. Neurotrophins and their receptors: a convergence point for many signaling pathways. Nat Rev Neurosci 2003; 4: 299-309. Review.

67. Huang EJ, Reichardt LF. Trk receptors: roles in neuronal signal transduction. Annu Rev Biochem 2003; 72: 609-642.

68. Matrone $C$, Marolda R, Ciafrè S, Ciotti MT, Mercanti D, Calissano P. Tyrosine kinase NGF receptor switches from a pro-survival to a pro-apoptotic activity via Abeta-mediated phosphorylation. Proc Natl Acad Sci USA 2009; 106: 11358-11363.

69. Reynolds CH, Garwood CJ, Wray S, Price C, Kellie S, Perera T et al. Phosphorylation regulates tau interactions with Src homology 3 domains of phosphatidylinositol 3-kinase, phospholipase Cgamma1, Grb2, and Src family kinases. J Biol Chem 2008; 283: 18177-18186.

70. Russo C, Dolcini V, Salis S, Venezia V, Violani E, Carlo P et al. Signal transduction through tyrosine-phosphorylated C-terminal fragments of amyloid precursor protein via an enhanced interaction with Shc/Grb2 adaptor proteins in reactive astrocytes of Alzheimer's disease brain. J Biol Chem 2002; 277: 35282-35288.

71. Cruz JC, Tsai LH. Cdk5 deregulation in the pathogenesis of Alzheimer's disease. Trends Mol Med 2004; 10: 452-458. Review.

72. Williamson R, Scales T, Clark BR, Gibb G, Reynolds CH, Kellie S et al. Rapid tyrosine phosphorylation of neuronal proteins including tau and focal adhesion kinase in response to amyloid-beta peptide exposure: involvement of Src family protein kinases. J Neurosci 2002; 22: 10-20.

73. Zampieri N, Xu CF, Neubert TA, Chao MV. Cleavage of p75 neurotrophin receptor by alpha-secretase and gamma-secretase requires specific receptor domains. J Biol Chem 2005; 280: 14563-14571.

74. Li H, Wolfe MS, Selkoe DJ. Toward structural elucidation of the gamma-secretase complex. Structure 2009; 17: 326-334. Review.

75. Coulson EJ, May LM, Sykes AM, Hamlin AS. The role of the p75 neurotrophin receptor in cholinergic dysfunction in Alzheimer's disease. Neuroscientist 2009; 15: 317-323.
76. Sotthibundhu A, Sykes AM, Fox B, Underwood CK, Thangnipon W, Coulson EJ. Beta-amyloid(1-42) induces neuronal death through the p75 neurotrophin receptor. J Neurosci 2009; 28: 3941-3946.

77. Longo FM, Massa SM. Neurotrophin receptor-based strategies for Alzheimer's disease. Curr Alzheimer Res 2005; 2: 167-169. Review.

78. Castellani RJ, Zhu X, Lee HG, Moreira PI, Perry G, Smith MA. Neuropathology and treatment of Alzheimer disease: did we lose the forest for the trees? Expert Rev Neurother 2007; 7: 473-485.

79. Tuszynski MH. Nerve growth factor gene therapy in Alzheimer disease. Alzheimer Dis Assoc Disord 2007; 21: 179-189.

80. Bergami M, Rimondini R, Santi S, Blum R, Götz M, Canossa M. Deletion of TrkB in adult progenitors alters newborn neuron integration into hippocampal circuits and increases anxiety-like behavior. Proc Natl Acad Sci USA 2008; 105: 15570-15575.

81. Covaceuszach S, Capsoni S, Marinelli S, Pavone F, Ceci M, Ugolini G et al. In vitro receptor binding properties of a 'painless' NGF mutein, linked to hereditary sensory autonomic neuropathy type V. Biochem Biophys Res Commun 2010; 391: 824-829.

82. Johnson A. Ganstigmine. Chiesi. Curr Opin Investig Drugs 2003; 4: 868-873.

83. Tuszynski MH, Thal L, Pay M, Salmon DP, U HS, Bakay R et al. A phase 1 clinical trial of nerve growth factor gene therapy for Alzheimer disease. Nat Med 2005; 11: 551-555.

84. Longo FM, Yang T, Knowles JK, Xie Y, Moore LA, Massa SM. Small molecule neurotrophin receptor ligands: novel strategies for targeting Alzheimer's disease mechanisms. Curr Alzheimer Res 2007; 4: 503-506. Review.

85. Pehar M, Cassina P, Vargas MR, Xie Y, Beckman JS, Massa SM et al. Modulation of p75-dependent motor neuron death by a small non-peptidyl mimetic of the neurotrophin loop 1 domain. Eur J Neurosci 2006; 24: 1575-1580.

86. Mahoney MJ, Saltzman WM. Controlled release of proteins to tissue transplants for the treatment of neurodegenerative disorders. J Pharm Sci 1996; 85: 1276-1281.

87. Gu H, Long D, Song C, Li X. Recombinant human NGF-loaded microspheres promote survival of basal forebrain cholinergic neurons and improve memory impairments of spatial learning in the rat model of Alzheimer's disease with fimbria-fornix lesion. Neurosci Lett 2009; 453: 204-209.

88. Montalcini RL, Calissano P. The Nerve Growth Factor. Sci Am 1979; 240; 68-77. 